\title{
Meinungsfreiheit in der Rechtsprechungspraxis des Interamerikanischen Gerichtshofs für Menschenrechte
}

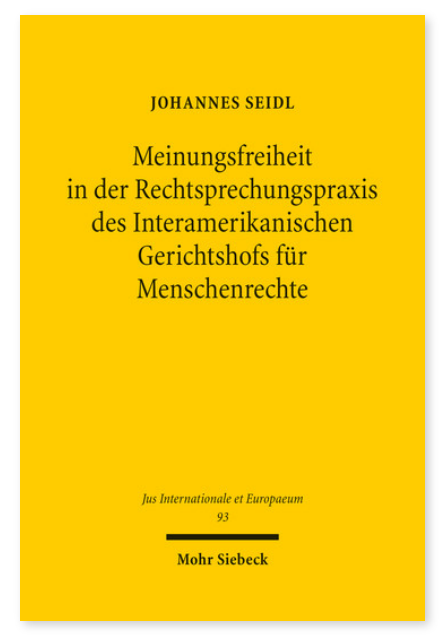

2014. XV, 267 Seiten. JusIntEu 93

ISBN 978-3-16-153340-2

DOI 10.1628/978-3-16-153340-2

eBook PDF 79,00€

ISBN 978-3-16-153339-6

fadengeheftete Broschur 79,00€
Mit dem Interamerikanischen Gerichtshof für Menschenrechte verfügt Lateinamerika über ein regionales Tribunal, das für die innerstaatlichen Demokratisierungsprozesse eine wichtige Rolle spielt. Neben der Aufarbeitung schwerer

Menschenrechtsverletzungen rückt zunehmend, auch angesichts der aktuellen politischen Situation in der Region, die Demokratiekonsolidierung ins Zentrum der Aufmerksamkeit. Ausgehend von Art. 13 und Art. 14 der Amerikanischen Menschenrechtskonvention (AMRK) analysiert Johannes Seidl die Konturen der Meinungsfreiheit im interamerikanischen System unter Berücksichtigung der Einflüsse der EMRK, des IPbpR sowie des US-Rechts. Neben dieser materiell-rechtlichen Seite beleuchtet er die innovative Tenorierung, die Durchsetzung der Entscheidungen sowie die Inkorporation interamerikanischer Standards in die nationalen Rechtsrahmen der Konventionsstaaten. Die Untersuchung verdeutlicht das Rezeptionspotential der interamerikanischen Praxis für den EGMR sowie den Afrikanischen Menschengerichtshof. Die Arbeit wurde mit dem Fakultätspreis der Juristenfakultät Leipzig (in Zusammenarbeit mit der Dr. Feldbausch-Stiftung) ausgezeichnet.

Johannes Seidl Geboren 1980; Studium der Rechtswissenschaften in Regensburg und Granada; Master of Laws (M.Jur) an der University of Oxford; 2009 Zweites Staatsexamen in Hamburg; 2010-12 Wissenschaftlicher Mitarbeiter an der FU Berlin; 2011 Visiting Fellow am Centro de Estudios en Libertad de Expresión y Acceso a la Información (CELE) in Buenos Aires; 2013 Promotion an der Universität Leipzig; seit 2012 Regierungsrat im Bundesministerium für Bildung und Forschung.

Jetzt bestellen:

https://mohrsiebeck.com/buch/meinungsfreiheit-in-der-rechtsprechungspraxis-des-interamerikanischen-gerichtshofs-fuermenschenrechte-9783161533402?no_cache=1

order@mohrsiebeck.com

Telefon: $+49(0) 7071-923-17$

Telefax: +49 (0)7071-51104 